\title{
Multi-morbidities of allergic rhinitis in adults: European Academy of Allergy and Clinical Immunology Task Force Report
}

\author{
C. Cingi i* P. Gevaert ${ }^{2}$, R. Mösges ${ }^{3}$, C. Rondon ${ }^{4}$, V. Hox ${ }^{5}$, M. Rudenko ${ }^{6}$, N. B. Muluk ${ }^{7}$, G. Scadding ${ }^{8}$, F. Manole ${ }^{9}$, \\ C. Hupin ${ }^{10}$, W. J. Fokkens ${ }^{11}$, C. Akdis ${ }^{12}$, C. Bachert ${ }^{2}$, P. Demoly ${ }^{13}$, J. Mullol ${ }^{14}$, A. Muraro ${ }^{15}$, N. Papadopoulos ${ }^{16}$, \\ R. Pawankar ${ }^{17}$, P. Rombaux ${ }^{18}$, E. Toskala ${ }^{19}$, L. Kalogjera ${ }^{20}$, E. Prokopakis ${ }^{21}$, P. W. Hellings ${ }^{5}$ and J. Bousquet ${ }^{13}$
}

\begin{abstract}
This report has been prepared by the European Academy of Allergy and Clinical Immunology Task Force on Allergic Rhinitis (AR) comorbidities. The aim of this multidisciplinary European consensus document is to highlight the role of multimorbidities in the definition, classification, mechanisms, recommendations for diagnosis and treatment of AR, and to define the needs in this neglected area by a literature review. AR is a systemic allergic disease and is generally associated with numerous multi-morbid disorders, including asthma, eczema, food allergies, eosinophilic oesophagitis (EOE), conjunctivitis, chronic middle ear effusions, rhinosinusitis, adenoid hypertrophy, olfaction disorders, obstructive sleep apnea, disordered sleep and consequent behavioural and educational effects. This report provides up-todate usable information to: (1) improve the knowledge and skills of allergists, so as to ultimately improve the overall quality of patient care; (2) to increase interest in this area; and (3) to present a unique contribution to the field of upper inflammatory disease.
\end{abstract}

Keywords: Adenoid hypertrophy, Allergic rhinitis (AR), Asthma, Chronic middle ear effusions, Comorbidities, Disordered sleep, Eczema, Eosinophilic oesophagitis (EoE), Conjunctivitis, Food allergies, Obstructive sleep apnea, Olfaction disorders, Rhinitis, Rhinosinusitis

\section{Introduction}

This report was prepared by the European Academy of Allergy and Clinical Immunology (EAACI) Task Force on "Allergic Rhinitis (AR) comorbidities". This was initiated, based on the rationale that AR is rarely found in isolation and needs to be considered in the context of systemic allergic disease associated with numerous comorbid disorders including asthma, chronic middle ear effusions, sinusitis, lymphoid hypertrophy with obstructive sleep apnea, disordered sleep, and consequent behavioural and educational effects.

$A R$, which has increased in prevalence over several decades, now affects $10-30 \%$ of the population, with the

\footnotetext{
*Correspondence: ccingi@gmail.com

1 Department of Otorhinolaryngology, Eskisehir Osmangazi University

School of Medicine, Eskisehir, Turkey

Full list of author information is available at the end of the article
}

greatest frequency found in children and adolescents [1]. It typically presents after the second year of life but the exact prevalence in early life is unknown. Since children's immune systems develop between the first and fourth years of life, those with an atopic predisposition begin to express allergic disease with a clear $\mathrm{Th}_{2}$ response to allergen exposure, resulting in symptoms, often beginning with atopic dermatitis (AD) and progressing to asthma and rhinitis (the allergic march) [1]. However after early childhood, AR is usually the initial manifestation of allergy [2].

AR is associated with numerous multi-morbid disorders. Those occurring in children have already been discussed in the EAACI Task Force on Paediatric Rhinitis [3]. This paper, by contrast, concerns itself largely with adult AR multimorbidities, but includes relevant paediatric data. 


\section{Definition}

Multimorbidity is the presence of one or more additional disorders (or diseases) co-occurring with a primary disease or disorder; or the effect of such additional disorders or diseases [4]. When the primary organ is not known, the term multimorbidity should be used instead of co-morbidity. In allergic diseases, the term should be multimorbidity.

\section{Multi-morbidities of allergic rhinitis}

AR is an organ-specific manifestation of allergic disease. As such, it coexists with other organ-specific disorders that have a common allergic basis. It is therefore rarely found in isolation but frequently has associated multimorbid disorders [5].

These can be subdivided into:

(a) Disorders which are part of the spectrum of allergic diseases, e.g. asthma, AD, food allergy, anaphylaxis;

(b) Disorders anatomically related to the nose: conjunctivitis, sinusitis, middle ear problems, throat and laryngeal effects;

(c) Sleep problems and secondary effects on concentration and behaviour; and

(d) Turbinate hypertrophy.

Although more common in paediatric practice, the occurrence of multi-morbidities in adults is significant and has important implications for quality of life, and work attendance and performance. It is likely that those with severe chronic upper airways disease (SCUAD) suffer more severe co-morbid effects.

\section{Asthma}

\section{Extent of co-occurrence}

A European study of over 20,000 children showed that the co-existence of eczema, asthma and rhinitis in the same child is more frequent than expected if they were independent entities. Those children with one of these diseases at age 4 were 4-7 times more likely to have two or three of them at age 8 . Children with two or three allergic diseases at 4 years are 30-60 times more likely to have two or three of these diseases at age 8 [6].

The association between asthma and rhinitis in adults has been recognized for some decades, since the pioneering study of Brydon [7], who showed that the majority of 1000 asthmatics also had rhinitis, which preceded their asthma in $45 \%$ of the subjects.

In fact the majority of inflammatory asthma sufferers have some form of upper airway disease (ARIA 2001) [8], either AR, non-allergic rhinitis or rhinosinusitis, usually with nasal polyposis (EPOS 2012) [9]. The extent of inflammation is usually proportional between upper and lower respiratory tracts with equivalence in eosinophils [10] and clinical severity [11].

Several possible relations exist between AR and asthma: (a) AR may be statistically associated with asthma; (b) AR may exacerbate coexisting asthma; and (c) AR may have a causal role in the pathogenesis of asthma.

Several possible causal mechanisms have been postulated to explain a link between AR and asthma:

- Lack of nasal function, i.e. purifying, warming and humidifying inspired air;

- Nasobronchial reflex (nasal irritants, allergens or cold stimuli);

- Rhinovirus adhesion theory (increased susceptibility to allergic inflammation and intracellular adhesion molecule (ICAM)-1 expression) [12]; and

- "Migration" of T cell responses to other tissues after initial sensitization. Braunstahl [13] has shown that allergen challenge in one part of the airway is followed by a response in all other parts;

- The idea of postnasal drip (carriage of inflammatory cytokines/mediators from nasopharynx to lower airways) has been largely abandoned, since the 'drip' travels to the gut, by virtue of the larynx, not to the lower airway, unless the subject is deeply unconscious.

Certainly the presence of rhinitis, both allergic and non-allergic, is a risk factor for subsequent asthma development [14].

\section{Effects of co-occurrence}

The co-existence of rhinitis is associated with poor asthma control in adults, adolescents and children [15]. Recent studies on AR and asthma are presented in Table 1 [16-19].

\section{Atopic dermatitis (AD) \\ Extent of co-occurrence}

In children, there are clear data concerning the co-occurrence of $A D$ and $A R$, largely from birth cohorts [20].

In one Taiwanese study [21], AR was the most common concomitant atopic disease associated with AD. The group with $\mathrm{AD}$ and $\mathrm{AR}$ was shown to be more likely to have serum mite-, cockroach- and feather-specific IgE, whereas the positive rates for wheat, peanut and soybean were higher in those with AD without rhinitis.

In a Croatian study [22], the age at onset was younger in the group of AD patients with concomitant AR, suggesting that $\mathrm{AD}$ multi-morbidity (although part of the allergic march) may be irrelevant to the later development of isolated respiratory allergy. 
Table 1 Asthma and AR

\begin{tabular}{|c|c|c|c|c|c|}
\hline References & Study type & No. patients & Age/Profile & Aim of the study & Results \\
\hline $\begin{array}{l}\text { Ciprandi } \\
\text { et al. [16] }\end{array}$ & Prospective & $\begin{array}{c}89(\mathrm{AR}), 940 \\
\text { (controls) }\end{array}$ & Adults & $\begin{array}{l}\text { Follow up of patients with } \\
\text { AR every } 2 \text { years for } 8 \text { years } \\
\text { to investigate spirometric } \\
\text { abnormalities/BHR }\end{array}$ & $\begin{array}{l}34 \text { of } 89 \text { AR patients developed BHR after } \\
8 \text { years } \\
\text { Sensitization to mite, birch and parietaria, } \\
\text { as well as rhinitis duration are risk factors }\end{array}$ \\
\hline $\begin{array}{l}\text { Navarro } \\
\text { et al. [17] }\end{array}$ & $\begin{array}{l}\text { Epidemiologic pro- } \\
\text { spective; multi centre }\end{array}$ & $\begin{array}{l}942 \text { (with } \\
\text { asthma) }\end{array}$ & $\begin{array}{l}\text { Mean age: } 35.5 \\
63 \% \text { female }\end{array}$ & $\begin{array}{l}\text { Investigate the link between } \\
\text { the upper and lower } \\
\text { airways }\end{array}$ & $\begin{array}{l}89.5 \% \text { had } A R \\
\text { Correlation between severity of rhinitis } \\
\text { and asthma }(p<0001) \text { and inverse } \\
\text { correlation with age }(p<0.0001) \text { and } \\
\text { severity of asthma }(p<0.05)\end{array}$ \\
\hline \multirow[t]{2}{*}{ Ko et al. [18] } & $\begin{array}{l}\text { Cross sectional; ques- } \\
\text { tionnaire }\end{array}$ & $\begin{array}{l}600 \text { (with } \\
\text { asthma) }\end{array}$ & $\begin{array}{l}267 \text { male; } 333 \\
\text { female }\end{array}$ & $\begin{array}{l}\text { Evaluation of prevalence of } \\
\text { AR in asthma }\end{array}$ & $\begin{array}{l}\text { 77\% of asthmatics had rhinitis in the past } \\
12 \text { months (of whom 96\% were previ- } \\
\text { ously diagnosed with AR) }\end{array}$ \\
\hline & & & & & $\begin{array}{l}\text { In patients with asthma and rhinitis, } 49 \% \\
\text { use nasal steroids, resulting in fewer ED } \\
\text { visits (13 vs } 25 \% \text { ) and fewer hospitaliza- } \\
\text { tions for asthma (5 vs 13\%) }\end{array}$ \\
\hline \multirow[t]{3}{*}{$\begin{array}{l}\text { Valero et al. } \\
\text { [19] }\end{array}$} & $\begin{array}{l}\text { Cross-sectional inter- } \\
\text { national population } \\
\text { study; based on } \\
\text { questionnaire }\end{array}$ & $\begin{array}{l}\text { 3225; } 1 \text { posi- } \\
\text { tive skin test }\end{array}$ & $\begin{array}{l}\text { Age range: } 10-50 ; \\
53 \% \text { male }\end{array}$ & $\begin{array}{l}\text { Evaluation of the link } \\
\text { between AR, asthma and } \\
\text { skin test sensitization }\end{array}$ & Asthma presents in $49 \%$ of AR patients \\
\hline & & & & & $\begin{array}{l}\text { Asthma severity was associated with } \\
\text { length of time from onset and with } \\
\text { allergic rhinitis severity }\end{array}$ \\
\hline & & & & & $\begin{array}{l}\text { Patients with asthma have a higher } \\
\text { number of allergen sensitizations and } \\
\text { higher sensitization intensity than those } \\
\text { without asthma }(p<0.01)\end{array}$ \\
\hline
\end{tabular}

Taken together these observations suggest that sensitization in later onset allergy is not via the skin, but by inhalant allergens acting via the respiratory tract mucosa [2].

\section{Effects of co-occurrence}

While some data suggest that the greater extent of allergic disease promotes more severe reactions [23, 24], other researchers note an inverse relationship between exacerbations in skin and in the respiratory tract [25].

In patients with asthma, $\mathrm{AD}$ and $\mathrm{AR}$, the risks of systemic glucocorticoid bioavailability are highest, since treatment is likely to be directed to three sites: skin, bronchi and nose. Absorption occurs (from least to greatest rate) in the nasal mucosa, followed by the bronchi, then the skin. Alternative means of treatment (such as allergen avoidance, saline douching, antihistamines, anti-leukotrienes, immunotherapy and anti-cytokines) may need to be considered.

\section{Food allergy}

\section{Extent of co-occurrence}

AR can be associated with primary food allergy; however, it is more frequently associated with secondary food allergy, also known as pollen food syndrome (PFS). Some medical professionals refer to pollen food syndrome as oral allergy syndrome (OAS), although strictly speaking the two are not the same. When the term OAS was first used in 1987 it had no connection with pollen allergy but referred to any allergic symptoms in the mouth that often preceded more serious symptoms. The term pollen food syndrome is preferred when referring to those allergy symptoms to food that are linked to pollen allergy, are limited to the mouth and throat, and are usually mild. [26]. The most typical example is the crossreactivity in patients with birch pollen AR who develop oral symptoms when eating apples, hazelnut, celery, etc. Typically, when these foods are cooked or processed they can be eaten without causing allergic reactions. Allergic reactions in secondary allergy are usually less severe than in primary food allergy [27]. Common symptoms, which usually come on immediately, include: redness, mild swelling or itching of the lips, tongue, inside of the mouth, soft palate and ears, itching and mild swelling affecting the throat. Occasionally, people might also experience symptoms in the oesophagus (gullet) or stomach, causing abdominal pain, nausea and even vomiting. Sneezing, runny nose, or eye symptoms can also occur.

Those sensitised to both birch and grass pollens are more likely to develop pollen food syndrome [28, 29]. They may also experience symptoms to a wider range of fresh fruits and raw vegetables than those who are sensitised to birch pollen alone. 
In one Italian study of pollen sensitive AR subjects aged 4-18 years old, a longer AR duration was significantly associated with moderate-to-severe AR symptoms $(\mathrm{p}=0.004)$, and with co-morbidities such as asthma ( $\mathrm{p}$ $0.030)$, PFS was present in $24 \%(\mathrm{p}<0.001)$ [30]. In a study of 110 UK adults with spring hay fever, 52 participants (47\%) were diagnosed with PFS, which is the commonest form of food allergy in the UK [29].

Interestingly, birth order effects differ for different allergic disorders in a large Japanese study of 14,669 schoolchildren aged 7-15 years [31]. There was no significant difference in the prevalence of BA or AD according to birth order, whereas the prevalence of AR, allergic conjunctivitis and FA decreased significantly as birth order increased. This raises questions about the effects of hygiene on different allergic manifestations.

\section{Treatment}

PFS is usually a mild type of food allergy that occurs upon contact of the mouth and throat with raw fruits or vegetables containing epitopes also present in a pollen to which the subject is sensitized [32].

PFS is a problem in patients sensitized to various pollen allergens. There was clear association between PFS and polyvalent airborne allergy (69\%). Cross-reactivity patterns were typical (for example, tree pollen allergyintolerance of apples, carrots and potatoes; grass pollen allergy-intolerance of kiwi fruit and tomatoes). Subcutaneous SIT significantly alleviated PFS symptoms associated with ingestion of the responsible fruit and vegetables in patients [33].

The treatment is avoidance of the food(s) causing reaction(s). Adrenalin is only indicated if severe reactions are described in the medical history, or if there are reactions to processed food. For primary food allergy an experimental study of SIT using peanuts was suspended because of adverse reactions [34].

SIT for food allergy is reaching the point where it may soon be used routinely in clinical practice. Sublingual immunotherapy is effective for desensitization with a very favorable adverse event profile. Epicutaneous immunotherapy is also effective, most notably in younger children, with a high rate of local reactions. Oral immunotherapy demonstrates high efficacy, but with a higher risk of gastrointestinal and systemic adverse events. The need for long-term application to sustain desensitization is currently unclear. Immunomodulatory adjuvants may be added to enhance or diminish the immunogenicity of proteins, whereas genetic modifications of food allergens are designed to limit the risk of adverse reactions and address the issues of standardization and supply [35].

The most common pollen-fruit cross-reaction is the birch-apple syndrome [36]. Mauro et al. [36] investigated patients with birch-apple syndrome to evaluate the outcome of subcutaneous immunotherapy (SCIT) and sublingual immunotherapy (SLIT). Two of 8 SCIT-treated patients (25\%) and 1 of 7 SLIT-treated patients (14.2\%) developed complete tolerance to apple. In the remaining patients, an increase in the provocative dose was found in 3 of the SCIT-treated (37.5\%) and 2 of the SLITtreated patients $(28.6 \%)$. They concluded that different doses of birch extract may be needed in different patients to improve the associated apple allergy and that a finer diagnostic work-up in selecting patients with birch-apple syndrome who are candidates to respond to birch pollen IT also concerning apple allergy is required [36].

\section{Eosinophilic oesophagitis (EoE) Description}

EoE is currently defined as a "chronic, immune/antigenmediated esophageal disease characterized clinically by symptoms related to esophageal dysfunction and histologically by eosinophil-predominant inflammation" [37].

EoE is a clinicopathologic disorder diagnosed by clinicians taking into consideration both clinical and pathologic information:

- Symptoms related to esophageal dysfunction;

- Eosinophil-predominant inflammation on esophageal biopsy, which is required for diagnosis, characteristically consisting of a peak value of $\geq 15$ eos per high power field (eos/hpf) [38];

- Response to treatment (dietary elimination; topical corticosteroids) supports, but it is not required, for diagnosis (Strong recommendation, low evidence) [37].

\section{Extent of co-occurrence}

EoE is commonly associated with other atopic diatheses (e.g. food allergy, asthma, eczema, chronic rhinitis, environmental allergies) [39]. In adults, solid food dysphagia is the most common presenting symptom [40, 41], with food impaction necessitating endoscopic bolus removal occurs in $33-54 \%$ of adult EoE patients [42]. Other symptoms in adults include chest pain, heartburn and upper abdominal pain $[38,43]$.

\section{Treatment}

- Acid suppression Approximately one-third of patients with suspected eosinophilic esophagitis have a good clinical and histologic response to proton pump inhibitors (PPIs alone, suggesting that GERD, or a PPI-responsive form of esophageal eosinophilia, may be responsible $[44,45]$.

- Dietary therapy is an effective treatment for eosinophilic esophagitis in children and adults. Dietary 
therapy is based upon the observation that patients with eosinophilic esophagitis have high rates of food allergies, and that those allergies may contribute to the development of eosinophilic esophagitis [44].

Topical corticosteroids have been proven to be an effective therapy for EoE and are a first-line therapy. Whilst available as multi-dose inhalers or aqueous nebulizer solutions for use in asthma, to treat EoE the medication is swallowed rather than inhaled to coat the esophagus and provide topical medication delivery (Recommendation strong, evidence high) [38].

Oral prednisone (a synthetic corticosteroid drug) may be useful to treat EoE if topical steroids are not effective or in patients who require rapid improvement in symptoms (Recommendation conditional, evidence low) [38].

Patients without symptomatic and histologic improvement after topical steroids might benefit from a longer course of topical steroids, higher doses of topical steroids, systemic steroids, an elimination diet or esophageal dilatation (Recommendation conditional, evidence low) [38].

- Esophageal dilation Dilation of esophageal strictures is effective for relieving dysphagia, but has no effect on underlying inflammation [46, 47].

- Other experimental treatments Prostaglandin D2 receptor antagonist [48], leukotriene inhibitors (Montelukast) [49], Mepolizumab: humanized monoclonal antibody against interleukin (IL)-5 [50], purine analogues (Azathioprine or 6-mercaptopurine) $[44,51]$.

\section{Allergic conjunctivitis \\ Extent of co-occurrence}

Allergic conjunctivitis is the typical conjunctival reaction in AR. It occurs following exposure to allergens. Ocular symptoms occur in $50-70 \%$ of patients with rhinitis, being more common with outdoor than with indoor allergens [52]. Pitt et al. [53] reported that seasonal allergic conjunctivitis (SAC) is associated with significant reductions in both ocular and general quality of life.

\section{Effects of co-occurrence}

Eye symptoms include itching, watering, redness and difficulty with vision due to these. Ocular symptoms are reduced by nasal air filters [54], suggesting that some eye involvement is secondary to nasal reflexes.

\section{Treatment}

Some INS reduce eye symptoms as well as nasal ones, the recent molecules appear more consistently effective [55]. The combination of intranasal antihistamine plus INS shows greater efficacy on rhinoconjunctivitis [56]. The topical ocular antihistamines, antazoline, azelastine, and emedastine, provide rapid relief of the symptoms of allergic conjunctivitis [57].

\section{Rhinosinusitis \\ Extent of co-occurrence}

The extent of co-occurrence of rhinosinusitis is disputed and is likely to be different in acute rhinosinusitis (ARS), chronic rhinosinusitis (CRS) and CRS with nasal polyposis.

\section{Effects of co-occurrence}

When considering the role of allergy in sinus disease, it can be speculated that nasal inflammation induced by IgE-mediated mechanisms favours the development of acute and/or chronic sinus disease [58, 59].

Several mechanisms could explain the link between allergic inflammation and sinus disease. Allergic inflammation of the nasal mucosa may give rise to mucosal congestion leading to impaired mucus drainage at the ostiomeatal complex in predisposed patients. Ostiomeatal pathology is considered to be essential to the generation of sinus-related symptoms [59].

Certainly, AR sufferers experience common colds (which are a form of acute rhinosinusitis) more severely and for longer than those without underlying minimal persistent inflammation [11]. The contribution of AR to chronic rhinosinusitis is less clear (EPOS 2012) [9]. One study has demonstrated that, in children, the degree of atopy (as reflected by the number of aeroallergen sensitivities or the presence of atopic multi-morbidities) is not associated with progression to CRS in the pediatric age group [60].

Symptoms of IgE-mediated allergic inflammation should be asked for during history taking in patients with CRS and specific allergy evaluation should be performed in case of clinical suspicion. With regard to treatment, it is recommended that anti-allergic therapy is added to the treatment of patients with chronic sinus disease and concomitant allergy [61].

\section{Chronic rhinosinusitis with nasal polyps (CRSwNP)}

Chronic rhinosinusitis with nasal polyps (CRSwNP) is associated with high concentrations of IgE in nasal polyp (NP) tissue. CRSwNP often coexists with asthma and this group is particularly characterized with tissue eosinophilia and high local IgE levels [62]. Therefore, an allergic aetiology of NPs has been presumed, though never firmly demonstrated. Between 0.5 and $4.5 \%$ of subjects with AR have NPs, which compares with the normal population [9]. In a retrospective study by Settipane and Chafee [63], the nasal polyps were present in $4.2 \%$ of the total 
population of 4986 subjects. Nasal polyp frequency rate was $6.7 \%$ in asthmatic patients and $2.2 \%$ in the rhinitis alone group. Of the total 211 cases of nasal polyps, $71 \%$ had asthma and $29 \%$ had rhinitis alone [63]. Pang et al. [64] reported that food allergen intradermal tests were more positive in nasal polyp patients (81\%) compared to controls (11\%).

In mucosal tissues, mRNA for the $\varepsilon$-chain of IgE was associated with a significant proportion of B cells [65, 66]. Recent evidence has shown local IgE synthesis, local receptor revision, class switch recombination and B-cell differentiation into IgE-secreting plasma cells in NPs [64]. In NPs, the level of IgE is independent of the atopic status of the patient $[65,67,68]$ whereas specific IgE in NPs is only partly related to skin prick test positivity $[65,67$, 68]. The local IgE in NPs is the result of two types of $\operatorname{IgE}$ production: systemic allergic IgE formation and a local polyclonal IgE formation [65, 66]. Local polyclonal IgE correlates with the presence of Staphylococcus aureus enterotoxins (SAE) [9, 65-67]. Finally, Gevaert et al. [69] demonstrated that antagonizing IgE by injections of omalizumab is effective for both allergic and nonallergic CRSwNP. The later finding proves the relevance of local mucosal IgE.

CRSwNP is an IgE mediated disease; however, the role of atopy is less clear.

\section{Otitis media with effusion (OME)}

\section{Extent of co-occurrence}

In one hospital population of children with chronic OME, over $80 \%$ had rhinitis [70]. A population survey in Slough schools (in the UK) also demonstrated an association between OME type symptoms and rhinitis [71].

OME is much rarer in adults and is usually found in association with more severe rhinosinusitis (such as aspirin exacerbated respiratory disease, allergic fungal sinusitis and Churg Strauss syndrome) rather than with rhinitis [9].

\section{Effects of co-occurrence}

The Eustachian tube exerts a major function in middle ear homeostasis via its role in the ventilation and protection of the middle ear and mucociliary clearance. The Eustachian tube contains an allergic inflammatory infiltrate in AR patients [72]. It is therefore not surprising that allergic inflammation with concomitant mucosal swelling may impair the function of the Eustachian tube [73].

Concomitant occurrence of allergic diseases and primary immune deficiencies was reported by Klemola [74]. Klemola [74] reported that $50 \%$ of the children with atopic disease had selective IgA deficiency (sIgAD). In allergic diseases such as asthma, atopic dermatitis, allergic rhinitis, and conjunctivitis, there is predisposition to infections resulting from an immunodeficiency [75].
Immune deficiencies and infections may contribute to the development of OME.

\section{Treatment}

Because of the pathophysiological associations of AR with OME, treatments focusing on allergic inflammation may be helpful in the management of OME [76]. A meta-analysis of 16 randomized controlled trials demonstrated no significant benefit from antihistamines, decongestants, or combined antihistamines and decongestants versus placebo for treatment of OME [77]. Intranasal corticosteroids did reduce the need for surgery in a double blind study in which autoinflation of the middle ear was also effective, but the combination of the two was less efficacious [78].

Atopic status and nasal disease should be evaluated in recurrent or chronic OME patients who have had no response to antibiotic therapy, and INS could be used as an adjunct to treatment of some OME patients. Further studies are needed to elucidate whether atopic status or rhinitis itself may influence the development of OME and the extent of ear involvement in various forms of rhinosinusitis.

\section{Adenoid hypertrophy (AH)}

The adenoid tissue is a peripheral lymphoid organ located in the nasopharynx, forming part of Waldeyer's ring. It contributes to the development of immunity against inhaled micro-organisms in early life. The volume of the adenoid increases with age and is maximal at 5-6 years, followed by a gradual decrease in volume by the age of 8-9 years [79]. Symptoms related to AH are nasal obstruction, open mouth breathing and snoring. 'Adenoid face' can be caused by AH or by severe obstructive rhinitis [61].

\section{Extent of co-occurrence}

Children with AR appear to have a greater susceptibility to $\mathrm{AH}$ than non-allergic children, with IgE-mediated inflammation of the nasal mucosa likely playing a role in both conditions [80].

Adenoid hypertrophy in adults is rare and may indicate underlying malignancy or infection, such as human immune deficiency virus (HIV), rather than allergy.

\section{Treatment}

Treatment of AR with intranasal corticosteroids has been shown to improve various parameters associated with adenoid hypertrophy [81].

\section{Olfactory dysfunction \\ Extent of co-occurrence}

In a recent study of 51 subjects with AR, half had hyposmia [82]. Half of AR subjects with a normal CT scored 
in the 30th percentile in an olfactory test. The degree of olfactory dysfunction does not seem to be related to the degree of nasal obstruction/nasal resistance [82], although with perennial (persistent) AR, the olfactory dysfunction seems to be more stable and more persistent throughout the year [83].

Reduced olfaction is more common in chronic rhinosinusitis, especially when NPs are present [9].

\section{Effects of co-occurrence}

AR may have a negative impact on olfactory function and is considered to be a sinonasal-related origin of chemosensory dysfunction [84]. This is probably secondary to a local inflammation in the nasal fossa and around the olfactory neuroepithelium in the olfactory cleft rather than a nasal obstruction impairing the odours to reach the olfactory cleft [82].

Olfactory function is a global perception of orthonasal and retronasal stimuli and of a stimulation of intranasal trigeminal nerve endings. The trigeminal function is enhanced in patients with AR and a link exists between chemosensory trigeminal function and neuroinflammation [85]. Antidromic activation of the trigeminal nerve after allergen and/or chemosensory stimuli leads to the liberation of neuropeptides and classical trigeminal related symptoms such as sneezing and itching.

\section{Treatment}

Systemic corticosteroid is the first-line-treatment for olfactory dysfunction of sinonasal origin but use must be short term because of side-effects. Topical corticosteroid does not reach the same efficacy but has a good safety profile [86]. Nasal corticosteroids have a positive impact on AR-related olfactory dysfunction [87]. However, most studies have used a visual analogue scale to evaluate olfactory function, which is known to be a poor tool in comparison with other test modalities such as threshold, discrimination or identification tasks in olfactory testing.

Antihistamines also have a positive effect on the olfactory function even if prescribed for a short period of time [88]. Olfactory dysfunction has marked effects on quality of life when severe and needs to be taken into account in the evaluation of comorbidities related to the presence of AR.

\section{Laryngitis, cough and vocal problems \\ Effects of co-occurrence}

The passage of mediators, cytokines and secretions backwards from the nose should not reach the larynx, unless epiglottic function is disturbed. However, many patients with AR do experience throat symptoms, including irritation, the sensation of difficult to shift mucus and cough [89]. In a recent study on AR and laryngeal symptoms, involving six controls and six adult singers, nasal provocation with pollen extracts caused a rapid induction of laryngeal irritation and globus sensation. However, no objective changes occurred then, nor during the pollen season [90].

\section{Treatment}

Edema of the laryngeal mucosa, laryngeal erythema and candidiasis may all be found in a minority of patients treated with inhaled glucocorticosteroids [91], but are not reported after the prolonged use of a nasal steroid spray.

\section{Gastro esophageal reflux (GER)}

Gastro esophageal reflux (GER) may masquerade as CRS [92]. Associations have been reported between GER and a variety of upper and lower respiratory tract conditions but not with AR [73].

\section{Obstructive sleep apnea (OSA) and sleep impairment}

The effect of AR on sleep can impair quality of life [93]. Patients with AR have more difficulties in falling asleep, take more sleeping drugs, suffer from nocturnal awakenings, and feel that they do not get sufficient sleep when compared to healthy controls [94].

\section{Treatment}

One study [93] has demonstrated an improvement in OSA in a short-term trial of intranasal fluticasone propionate. The mixed/obstructive apnea-hypopnea index decreased by $4.9 \pm 1.0$ events per hour in the fluticasone propionate group and increased by $2.2 \pm 3.3$ events per hour in the placebo group [94]. Craig et al. studied a group of 20 adults with perennial rhinitis and sleep complaints, examining the benefit of twice-daily nasal flunisolide using a double-blind, placebo-controlled, crossover study. They found that nasal congestion and subjective sleep improved significantly in the topical corticosteroid-treated subjects. They concluded that the fatigue in perennial allergies may be a result of nasal congestion and associated sleep fragmentation. Decreasing nasal congestion with nasal steroids may improve sleep, daytime fatigue, and the quality of life of patients with AR [95].

\section{Fatigue and learning impairment Extent of co-occurrence}

Patients with AR frequently complain of disordered sleep, daytime somnolence and inability to concentrate. Recent studies document daytime somnolence in children with AR. Craig et al. [95] reported an association between daytime somnolence and nasal congestion in a group of patients with AR. If nasal symptoms such as 
itching, sneezing, rhinorrhea, and congestion are not well controlled during the day, they may contribute to learning problems during school hours. If these symptoms are not well controlled during the night, they may contribute to nocturnal sleep loss, secondary daytime fatigue and learning impairment [96].

\section{Effects of co-occurrence}

Baraniuk et al. [97], in a study of chronic fatigue syndrome, failed to document an increase in AR in these patients. However, patients with AR (unlike the group with rheumatologic disease) had significantly increased symptoms of fatigue intermediate between levels of

Table 2 Diagnosis of multi-morbidities associated with allergic rhinitis (AR)

\begin{tabular}{|c|c|}
\hline Multi-morbidities of AR & Definitive medical history, symptoms and signs \\
\hline \multirow[t]{4}{*}{ Asthma } & Ask about any history of cough, wheeze, shortness of breath, exercise-induced bronchospasm \\
\hline & Examine the chest for wheeze, hyperexpansion \\
\hline & Assess peak expiratory flows and spirometry in older children preferably with reversibility testing with beta-2 agonists \\
\hline & If in doubt, undertake an exercise, mannitol or methacholine challenge test or measure exhaled nitric oxide (FENO) \\
\hline \multirow[t]{2}{*}{ Conjunctivitis } & Ask about a history of red, itchy, watery eyes, eye rubbing \\
\hline & Examine eyes \\
\hline \multirow[t]{3}{*}{ Rhinosinusitis } & Ask about a history of nasal obstruction or discharge (purulent) with or without hyposmia, headache, facial pain or cough \\
\hline & Undertake nasendoscopy in older children \\
\hline & $\begin{array}{l}\text { CT scan/sinus X-rays not recommended unless there are complications or failed therapy, unilateral symptoms or severe } \\
\text { disease unresponsive to medical therapy }\end{array}$ \\
\hline \multirow{7}{*}{$\begin{array}{l}\text { Otitis media with effusion } \\
\text { (OME)/impaired hearing }\end{array}$} & Ask questions related to immune deficiency and/or recurrent infections \\
\hline & $\begin{array}{l}\text { Ask about any speech and language delay, increasing volume of TV, shouting, poor concentration, failing performance at } \\
\text { school, frustration, irritability }\end{array}$ \\
\hline & Examine the ears using a pneumatic otoscope if possible, and Weber and Rinne tests \\
\hline & Use tympanoscopy for evaluation of tympanic membrane and middle ear \\
\hline & Undertake tympanometry \\
\hline & Use a whisper test to screen otitis media with effusion and hearing loss \\
\hline & Use audiometry in older children_-pure tones, speech \\
\hline \multirow{3}{*}{$\begin{array}{l}\text { Obstructive sleep apnea } \\
\text { and sleep problems }\end{array}$} & Enquire about any history of disturbed sleep, snoring, apnoea, tiredness, irritability \\
\hline & $\begin{array}{l}\text { Assess nasal airway using spatula misting, nasal inspiratory peak flow, visual examination of nostrils and nasendoscopy in older } \\
\text { children to view nasal airway and adenoids }\end{array}$ \\
\hline & Consider sleep study \\
\hline Atopic dermatitis & Ask about skin symptoms of itching, redness, rash \\
\hline \multirow[t]{2}{*}{ Food allergy } & Ask about symptoms related to food intake \\
\hline & $\begin{array}{l}\text { Ask for oral allergy syndrome (OAS): Allergic reaction that occurs upon contact of the mouth and throat with raw fruits or } \\
\text { vegetables which may be tolerated when cooked }\end{array}$ \\
\hline \multirow[t]{2}{*}{ Eosinophilic oesophagitis } & $\begin{array}{l}\text { Ask for symptoms related to esophageal dysfunction as solid food dysphagia, chest pain, heartburn and upper abdominal } \\
\text { pain }\end{array}$ \\
\hline & Assess esophageal biopsies \\
\hline \multirow[t]{3}{*}{ Adenoid hypertrophy } & Ask about nasal obstruction, open mouth breathing and snoring \\
\hline & Examine the face \\
\hline & Perform posterior rhinoscopy; nasal and nasopharyngeal rigid/flexible endoscopy \\
\hline \multirow[t]{2}{*}{ Olfactory dysfunction } & Ask for olfactory dysfunction, hyposmia, anosmia \\
\hline & Evaluate nasal airway and smell function tests \\
\hline \multirow{2}{*}{$\begin{array}{l}\text { Laryngitis, cough and } \\
\text { vocal problems }\end{array}$} & Ask for symptoms including irritation in the throat, the sensation of difficult to shift mucus and cough \\
\hline & Examine throat and larynx, see vocal cords and arytenoids \\
\hline \multirow[t]{2}{*}{ Gastro esophageal reflux } & Ask for symptoms of indigestion, regurgitation, cough \\
\hline & Examine throat and larynx \\
\hline \multirow{2}{*}{$\begin{array}{l}\text { Fatigue and learning } \\
\text { impairment }\end{array}$} & Ask about fatigue and learning impairment, school success \\
\hline & Ask about sleep quality, nasal obstruction and nasal discharge \\
\hline \multirow[t]{2}{*}{ Turbinate hypertrophy } & Ask about nasal obstruction \\
\hline & $\begin{array}{l}\text { Perform anterior rhinoscopy and nasal endoscopy, acoustic rhinometry pre and post decongestant shows whether } \\
\text { mucosal lining or bony structure is responsible }\end{array}$ \\
\hline
\end{tabular}


fatigue seen in normal subjects and patients with chronic fatigue syndrome.

AR can reduce driving performance [98]. It can also impair examination performance in adolescents [99].

\section{Treatment}

In a study involving major examinations, sedating antihistamines increased the likelihood of dropping an examination grade [99]. The medications used to treat allergic rhinitis may cause central nervous system adverse effects and contribute to learning impairment. The newer relatively nonsedating medications such as loratadine, cetirizine, and fexofenadine have less potential to impair central nervous system function and learning than their predecessors [96].

\section{Turbinate hypertrophy}

\section{Extent of co-occurrence}

In AR patients, nasal obstruction is a bothersome symptom which is most commonly due to inferior turbinate hypertrophy. The inferior turbinate is the initial deposit point for allergens and undergoes dynamic changes through the allergic cascade, which results in nasal obstruction. Targeting the inferior turbinate to augment the nasal airway is the mainstay of surgical treatment in AR [100].

\section{Effects of co-occurence}

The turbinates are tiny shelf-like bony structures that project into the nasal passageways. They help warm, humidify, and clean the air that passes over them. If turbinate hypertrophy develops, it causes persistent nasal congestion and, sometimes, pressure and headache in the middle of the face and forehead. This condition may require surgery [101].

\section{Treatment}

Turbinate hypertrophy which is multimorbidity of the AR is primarily treated by allergen avoidance and medical treatment, but when these measures fail to control symptoms then surgery to the inferior turbinates of nose can be performed [102]. Outfracture, submucous resection, laser vaporization, radiofrequency ablation, and coblation, cryosurgery, submucous electrocautery, and microdebriber turbinoplasty are treatment options in turbinate hypertrophy related to AR [103].

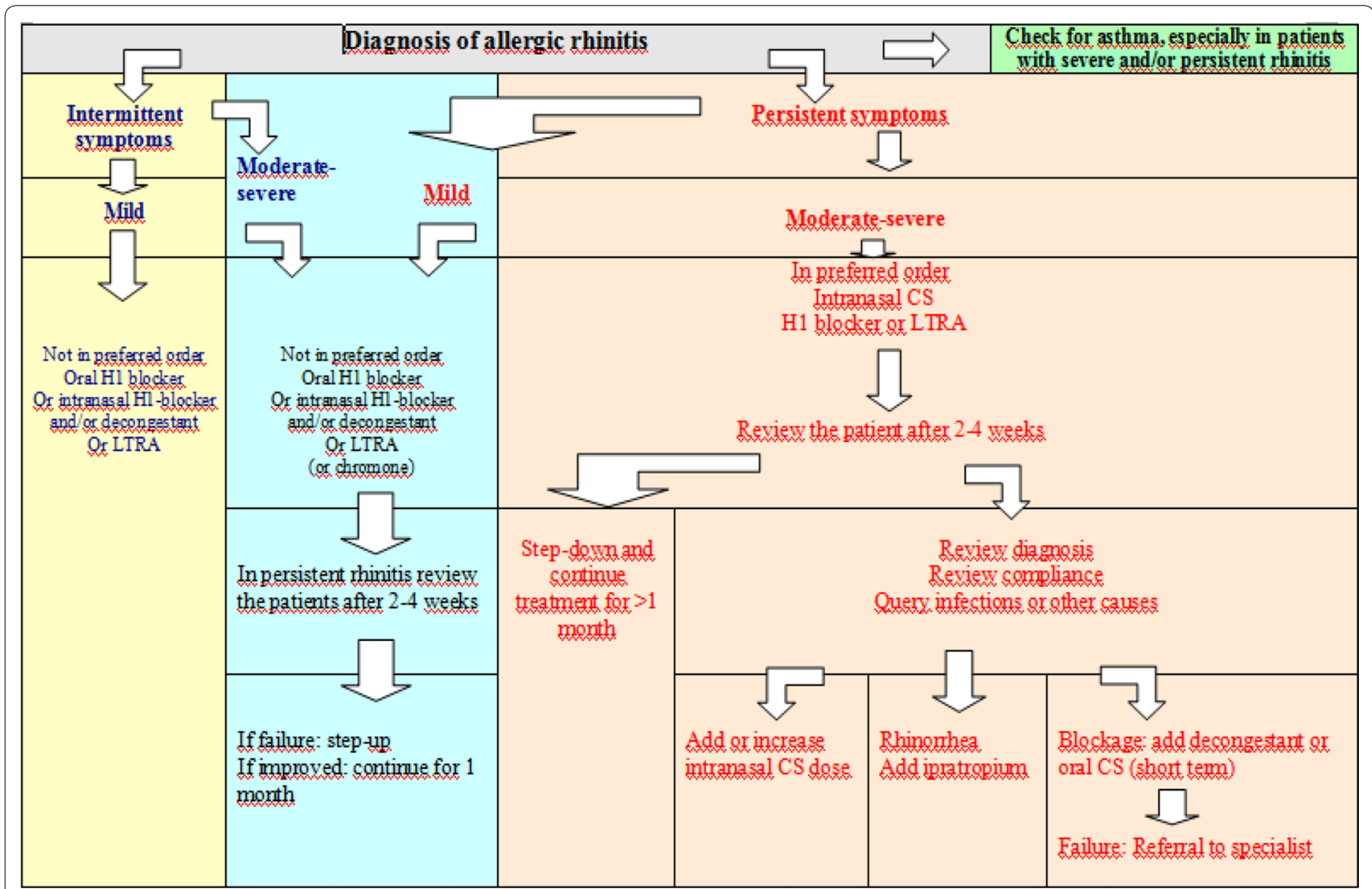

Fig. 1 Treatment for AR (taken from ARIA 2012) [104]. In addition to the pathways presented in the figure allergen and irritant avoidance may be appropriate; for conjunctivitis, add an oral H1-blocker, intraocular H1-blocker or intraocular cromone (or saline); consider specific immunotherapy when pharmacotherapy fails or is unacceptable to the patient 


\section{Diagnosis}

Diagnosis of multi-morbidities of $\mathrm{AR}$ are shown in Table 2 [3].

A physical examination of all organ systems potentially affected by allergies, with emphasis on the upper respiratory tract, should be performed in patients with a history of rhinitis.

\section{Treatment}

During the treatment of AR, multi-morbidities (co-morbidities) of AR should be considered. Treatment of AR according to guidelines may cause decreasing the nasal symptoms; and may cause improvement of the co-morbid problems; see Fig. 1 [104].

\section{Conclusion}

This EAACI Task Force Report on AR Multi-morbidities has defined and classified the multi-morbidities associated with $\mathrm{AR}$, together with providing recommendations for diagnosis and treatment. The information provided here should help improve allergists' knowledge and skills, ultimately improving the overall quality of patient care, as well as helping to raise the profile of this important area of work.

\section{Authors' contributions}

All authors contributed to design, planning, literature survey and writing.

\section{Author details}

${ }^{1}$ Department of Otorhinolaryngology, Eskisehir Osmangazi University School of Medicine, Eskisehir, Turkey. ${ }^{2}$ Upper Airway Research Laboratory, Ghent University Hospital, Ghent, Belgium. ${ }^{3}$ Institute of Medical Statistics, Informatics, and Epidemiology, Medical Faculty, University of Köln, Cologne, Germany. ${ }^{4}$ Allergy Unit, IBIMA, Regional University Hospital of Malaga, UMA, Malaga, Spain. ${ }^{5}$ Clinical division of Otorhinolaryngology, Head and Neck Surgery, University Hospitals Leuven, Louvain, Belgium. ${ }^{6}$ London Allergy and Immunology Centre, London, UK. ${ }^{7}$ ENT Department, Faculty of Medicine, Kirikkale University, Kirikkale, Turkey. ${ }^{8}$ Royal National Throat, Nose and Ear Hospital, London, UK. ${ }^{9}$ Faculty of Medicine, ENT Department, University of Oradea, Oradea, Romania. ${ }^{10}$ Institut de Recherche Expérimentale et Clinique (IREC), Pole de Pneumologie, ORL \& Dermatologie, Université catholique de Louvain, Louvain-la-Neuve, Belgium. ${ }^{11}$ Department of Otorhinolaryngology, Head and Neck Surgery, Academic Medical Centre (AMC), Amsterdam, The Netherlands. ${ }^{12}$ Christine Kuhne-Center for Allergy Research and Education, Swiss Institute of Allergy and Asthma Research, University of Zurich, Davos, Switzerland. ${ }^{13}$ Hôpital Arnaud de Villeneuve, University Hospital of Montpellier, Montpellier, France. ${ }^{14}$ Unitat de Rinologia i Clinica de I'Olfacte, Servei d'Otorinolaringologia, Hospital Clínic, Barcelona, Catalonia, Spain. ${ }^{15}$ The Referral Centre for Food Allergy Diagnosis and Treatment Veneto Region, Department of Mother and Child Health, University of Padua, Padua, Italy. ${ }^{16}$ Allergy Department, 2nd Pediatric Clinic, University of Athens, Athens, Greece. ${ }^{17}$ Nippon Medical School, Tokyo, Japan. ${ }^{18}$ Service d'ORL, Cliniques Universitaires St-Luc, Brussels, Belgium. ${ }^{19}$ Department of Otorhinolaryngology-Head and Neck Surgery, Temple University, Philadelphia, PA, USA. ${ }^{20}$ Department of Otorhinolaryngology and Head and Neck Surgery, University Hospital Sestre milosrdnice, Zagreb, Croatia. ${ }^{21}$ Department of Otorhinolaryngology, University Hospital of Crete, Crete, Greece.

\section{Competing interests}

The authors declare that they have no competing interests.

\section{Availability of data and materials}

The datasets used and/or analysed during the current study are available from the corresponding author on reasonable request.

\section{Consent for publication}

This paper is EAACI-ENT Section Task force Paper. It was approved by all authors and Executive Committee of EAACI (Excom).

\section{Ethics approval and consent to participate}

There is no Ethics approval, because this is a review paper. There is no need to have informed consent.

\section{Publisher's Note}

Springer Nature remains neutral with regard to jurisdictional claims in published maps and institutional affiliations.

Received: 1 February 2017 Accepted: 12 May 2017

Published online: 01 June 2017

\section{References}

1. Sih T, Mion O. Allergic rhinitis in the child and associated comorbidities. Pediatr Allergy Immunol. 2010;21:e107-13.

2. Scadding GK, Bousquet J. Introduction: allergic rhinitis. Allergy. 2007:62(Suppl 85):3-5.

3. Roberts G, Xatzipsalti M, Borrego LM, Custovic A, Halken S, Hellings PW, et al. Paediatric rhinitis: position paper of the European academy of allergy and clinical immunology. Allergy. 2013;68:1102-16.

4. Comorbidity [Internet]. Wikipedia, the free encyclopedia. http:// en.wikipedia.org/wiki/Comorbidity. Accessed 2 Dec 2013.

5. Lack G. Pediatric allergic rhinitis and comorbid disorders. J Allergy Clin Immunol. 2001;108(Suppl 1):S9-15.

6. Pinart M, Benet M, Annesi-Maesano I, von Berg A, Berdel D, Carlsen KC, et al. Comorbidity of eczema, rhinitis and asthma in lg-E sensitised and non-lgE-sensitised children in MeDALL: a population-based cohort study. Lancet Respir Med. 2014;2:131-40.

7. Brydon MJ. Skin prick testing in general practice. J Adv Nurs. 1998:27:442-4.

8. Bousquet J, Van Cauwenberge P, Khaltaev N, Aria Workshop Group, World Health Organization. Allergic rhinitis and its impact on asthma. J Allergy Clin Immunol. 2001;108(Suppl 5):S147-334.

9. Fokkens WJ, Lund VJ, Mullol J, Bachert C, Alobid I, Baroody F, et al. European Position paper on rhinosinusitis and nasal polyps 2012. Rhinol Suppl. 2012;23:3 p (preceding table of contents, 1-298).

10. Gaga M, Frew AJ, Varney VA, Kay AB. Eosinophil activation and Tlymphocyte infiltration in allergen-induced late phase skin reactions and classical delayed-type hypersensitivity. J Immunol. $1991 ; 147: 816-22$

11. Katelaris $\mathrm{CH}$, Linneberg A, Magnan A, Thomas WR, Wardlaw AJ, Wark P. Developments in the field of allergy in 2010 through the eyes of clinical and experimental allergy. Clin Exp Allergy. 2011;41:1690-710.

12. Ciprandi G, Pronzato C, Ricca V, Passalacqua G, Bagnasco M, Canonica GW. Allergen-specific challenge induces intercellular adhesion molecule 1 (ICAM-1 or CD54) on nasal epithelial cells in allergic subjects: relationships with early and late inflammatory phenomena. Am J Respir Crit Care Med. 1994;150:1653-9.

13. Braunstahl GJ. United airways concept: what does it teach us about systemic inflammation in airways disease? Proc Am Thorac Soc. 2009;6:652-4

14. Shaaban R, Zureik M, Soussan D, Neukirch C, Heinrich J, Sunyer J, et al. Rhinitis and onset of asthma: a longitudinal population-based study. Lancet. 2008:372:1049-57.

15. Clatworthy J, Price D, Ryan D, Haughney J, Horne R. The value of selfreport assessment of adherence, rhinitis and smoking in relation to asthma control. Prim Care Respir J. 2009;18:300-5.

16. Ciprandi G, Cirillo I, Signori A. Impact of allergic rhinitis on bronchi: an 8-year follow-up study. Am J Rhinol Allergy. 2011;25:e72-6. 
17. Navarro A, Valero A, Juliá B, Quirce S. Coexistence of asthma and allergic rhinitis in adult patients attending allergy clinics: ONEAIR study. J Investig Allergol Clin Immunol. 2008;18:233-8.

18. Ko FW, Ip MS, Chu CM, So LK, Lam DC, Hui DS. Prevalence of allergic rhinitis and its associated morbidity in adults with asthma: a multicentre study. Hong Kong Med J. 2010;16:354-61.

19. Valero A, Pereira C, Loureiro C, Martínez-Cócera C, Murio C, Rico P, et al. Interrelationship between skin sensitization, rhinitis, and asthma in patients with allergic rhinitis: a study of Spain and Portugal. J Investig Allergol Clin Immunol. 2009;19:167-72.

20. Mölter A, Simpson A, Berdel D, Brunekreef B, Custovic A, Cyrys J, et al. A multicentre study of air pollution exposure and childhood asthma prevalence: the ESCAPE project. Eur Respir J 2014. [Epub ahead of print]

21. Lee $\mathrm{CH}$, Chuang HY, Shih CC, Jee SH, Wang LF, Chiu HC, et al. Correlation of serum total IgE, eosinophil granule cationic proteins, sensitized allergens and family aggregation in atopic dermatitis patients with or without rhinitis. J Dermatol. 2004;31:784-93.

22. Lugović L, Lipozencić J. Are respiratory allergic diseases related to atopic dermatitis? Coll Antropol. 2000;24:335-45.

23. Solé D, Camelo-Nunes IC, Wandalsen GF, Melo KC, Naspitz CK. Is rhinitis alone or associated with atopic eczema a risk factor for severe asthma in children? Pediatr Allergy Immunol. 2005;16:121-5.

24. Silverberg Jl, Simpson EL. Association between severe eczema in children and multiple comorbid conditions and healthcare utilization. Pediatr Allergy Immunol. 2013;24:476-86.

25. Umeki S. Allergic cycle: relationships between asthma, allergic rhinitis, and atopic dermatitis. J Asthma. 1994;31:19-26.

26. Popescu F-D. Cross-reactivity between aeroallergens and food allergens. World J Methodol. 2015;26(5):31-50. doi:10.5662/wjm.v5.i2.31.

27. Caliskaner Z, Naiboglu B, Kutlu A, Kartal O, Ozturk S, Onem Y, et al. Risk factors for pollen food syndrome in patients with seasonal allergic rhinitis. Med Oral Patol Oral Cir Bucal. 2011;16:e312-6.

28. Asero R, Massironi F, Velati C. Detection of prognostic factors for pollen food syndrome in patients with birch pollen hypersensitivity. J Allergy Clin Immunol. 1996;2:611-6.

29. Skypala IJ, Calderon MA, Leeds AR, Emery P, Till SJ, Durham SR. Development and validation of a structured questionnaire for the diagnosis of pollen food syndrome in subjects with seasonal allergic rhinitis during the UK birch pollen season. Clin Exp Allergy. 2011:41:1001-11.

30. Dondi A, Tripodi S, Panetta V, Asero R, Businco AD, Bianchi A, et al. Pollen-induced allergic rhinitis in 1360 Italian children: comorbidities and determinants of severity. Pediatr Allergy Immunol. 2013;24:742-51.

31. Kusunoki T, Mukaida K, Morimoto T, Sakuma M, Yasumi T, Nishikomori $\mathrm{R}$, et al. Birth order effect on childhood food allergy. Pediatr Allergy Immunol. 2012;23:250-4.

32. Pongdee T. Pollen food syndrome (PFS). The American Academy of Allergy, Asthma \& Immunology (AAAAI). https://www.aaaai.org/ conditions-and-treatments/library/allergy-library/outdoor-allergiesand-food-allergies-can-be-relate. Accessed 30 Mar 2017.

33. Czarnecka-Operacz M, Jenerowicz D, Silny W. Oral allergy syndrome in patients with airborne pollen allergy treated with specific immunotherapy. Acta Dermatovenerol Croat. 2008;16:19-24.

34. Nelson HS, Lahr J, Rule R, et al. Treatment of anaphylactic sensitivity to peanuts by immunotherapy with injections of aqueous peanuts extract. J Allergy Clin Immunol. 1997;99:744-51.

35. Reisacher WR, Davison W. Immunotherapy for food allergy. Curr Opin Otolaryngol Head Neck Surg. 2017; . doi:10.1097/ $\mathrm{MO0} .0000000000000353$ [Epub ahead of print].

36. Mauro M, Russello M, Incorvaia C, Gazzola G, Frati F, Moingeon P, Passalacqua G. Birch-apple syndrome treated with birch pollen immunotherapy. Int Arch Allergy Immunol. 2011;156:416-22. doi:10.1159/000323909 [Epub 2011 Aug 10].

37. Liacouras CA, Furuta GT, Hirano I, Atkins D, Attwood SE, Bonis PA, et al. Eosinophilic esophagitis: updated consensus recommendations for children and adults. J Allergy Clin Immunol. 2011;128:3-20.

38. Dellon ES, Gonsalves N, Hirano I, Furuta GT, Liacouras CA, Katzka DA, American College of Gastroenterology. ACG clinical guideline: evidenced based approach to the diagnosis and management of esophageal eosinophilia and eosinophilic esophagitis (EoE). Am J Gastroenterol. 2013;108:679-92 (quiz 693).
39. Furuta GT, Liacouras CA, Collins MH, Gupta SK, Justinich C, Putnam $P E$, et al. Eosinophilic esophagitis in children and adults: a systematic review and consensus recommendations for diagnosis and treatment. Gastroenterology. 2007;133:1342-63.

40. Prasad GA, Talley NJ, Romero Y, Arora AS, Kryzer LA, Smyrk TC, et al. Prevalence and predictive factors of eosinophilic esophagitis in patients presenting with dysphagia: a prospective study. Am J Gastroenterol. 2007;102:2627-32.

41. Mackenzie SH, Go M, Chadwick B, Thomas K, Fang J, Kuwada S, et al. Eosinophilic esophagitis in patients presenting with dysphagia: a prospective analysis. Aliment Pharmacol Ther. 2008;28:1140-6.

42. Desai TK, Stecevic V, Chang CH, Goldstein NS, Badizadegan K, Furuta GT. Association of eosinophilic inflammation with esophageal food impaction in adults. Gastrointest Endosc. 2005;61:795-801.

43. Fass R, Gasiorowska A. Refractory GERD: what is it? Curr Gastroenterol Rep. 2008;10:252-7.

44. Bomis PAL, Furuta GT. Treatment of eosinophilic esophagitis. In: Talley NJ, Grover S, editors. UpToDate. https://www.uptodate.com/contents/ treatment-of-eosinophilic-esophagitis\#H209980. Accessed 31 Mar 2017.

45. Peterson KA, Thomas KL, Hilden K, et al. Comparison of esomeprazole to aerosolized, swallowed fluticasone for eosinophilic esophagitis. Dig Dis Sci. 2010;55:1313.

46. Schoepfer AM, Gonsalves N, Bussmann C, et al. Esophageal dilation in eosinophilic esophagitis: effectiveness, safety, and impact on the underlying inflammation. Am J Gastroenterol. 2010;105:1062.

47. Robles-Medranda C, Villard F, le Gall C, et al. Severe dysphagia in children with eosinophilic esophagitis and esophageal stricture: an indication for balloon dilation? J Pediatr Gastroenterol Nutr. 2010;50:516.

48. Straumann A, Hoesli S, Bussmann Ch, et al. Anti-eosinophil activity and clinical efficacy of the CRTH2 antagonist OC000459 in eosinophilic esophagitis. Allergy. 2013;68:375.

49. Attwood SE, Lewis CJ, Bronder CS, et al. Eosinophilic oesophagitis: a novel treatment using Montelukast. Gut. 2003:52:181.

50. Straumann A, Conus S, Grzonka P, et al. Anti-interleukin-5 antibody treatment (mepolizumab) in active eosinophilic oesophagitis: a randomised, placebo-controlled, double-blind trial. Gut. 2010;59:21.

51. Netzer P, Gschossmann JM, Straumann A, et al. Corticosteroid-dependent eosinophilic oesophagitis: azathioprine and 6-mercaptopurine can induce and maintain long-term remission. Eur J Gastroenterol Hepatol. 2007:19:865.

52. Bonini S, Coassin M, Aronni S, Lambiase A. Vernal keratoconjunctivitis. Eye (Lond). 2004; 18:345-51.

53. Pitt AD, Smith AF, Lindsell L, Voon LW, Rose PW, Bron AJ. Economic and quality-of-life impact of seasonal allergic conjunctivitis in Oxfordshire. Ophthalmic Epidemiol. 2004;11:17-33.

54. O'Meara TJ, Sercombe JK, Morgan G, Reddel HK, Xuan W, Tovey ER. The reduction of rhinitis symptoms by nasal filters during natural exposure to ragweed and grass pollen. Allergy. 2005;60(4):529-32.

55. Keith PK, Scadding GK. Are intranasal corticosteroids all equally consistent in managing ocular symptoms of seasonal allergic rhinitis? Curr Med Res Opin. 2009;25:2021-41 (Review. Erratum in: Curr Med Res Opin 2010; 26:177. Curr Med Res Opin 2010; 26:990).

56. Azelastine/fluticasone propionate (Dymista) for seasonal allergic rhinitis. Med Lett Drugs Ther. 2012; 54:85-7.

57. Williams PB, Crandall E, Sheppard JD. Azelastine hydrochloride, a dualacting anti-inflammatory ophthalmic solution, for treatment of allergic conjunctivitis. Clin Ophthalmol. 2010;7(4):993-1001.

58. Rachelefsky GS, Goldberg M, Katz RM, Boris G, Gyepes MT, Shapiro MJ, et al. Sinus disease in children with respiratory allergy. J Allergy Clin Immunol. 1978;61:310-4.

59. Scadding GK. Recent advances in the treatment of rhinitis and rhinosinusitis. Int J Pediatr Otorhinolaryngol. 2003;67:S201-4.

60. Sedaghat AR, Phipatanakul W, Cunningham MJ. Atopy and the development of chronic rhinosinusitis in children with allergic rhinitis. J Allergy Clin Immunol Pract. 2013;6:689-91.

61. Hellings PW, Fokkens WJ. Allergic rhinitis and its impact on otorhinolaryngology. Allergy. 2006;61:656-64.

62. Bachert C, Zhang N, Holtappels G, De Lobel L, van Cauwenberge P, Liu $\mathrm{S}$, et al. Presence of IL-5 protein and IgE antibodies to staphylococcal enterotoxins in nasal polyps is associated with comorbid asthma. J Allergy Clin Immunol. 2010;126:962-8. 
63. Settipane GA, Chafee FH. Nasal polyps in asthma and rhinitis: a review of 6,037 patients. J Allergy Clin Immunol. 1977;59:17-21.

64. Pang YT, Eskici O, Wilson JA. Nasal polyposis: role of subclinical delayed food hypersensitivity. Otolaryngol Head Neck Surg. 2000;122:298-301.

65. Gevaert P, Holtappels G, Johansson SG, Cuvelier C, Cauwenberge P, Bachert C. Organization of secondary lymphoid tissue and local IgE formation to Staphylococcus aureus enterotoxins in nasal polyp tissue. Allergy. 2005;60:71-9.

66. Gevaert P, Nouri-Aria KT, Wu H, Harper CE, Takhar P, Fear DJ, et al. Local receptor revision and class switching to IgE in chronic rhinosinusitis with nasal polyps. Allergy. 2013;68:55-63.

67. Van Zele T, Gevaert P, Holtappels G, van Cauwenberge P, Bachert C. Local immunoglobulin production in nasal polyposis is modulated by superantigens. Clin Exp Allergy. 2007;37:1840-7.

68. Bachert C, Gevaert P, Holtappels G, Johansson SGO, Van Cauwenberge $P$. Total and specific lgE in nasal polyps is related to local eosinophilic inflammation. J Allergy Clin Immunol. 2001;107:607-14

69. Gevaert P, Calus L, Van Zele T, Blomme K, De Ruyck N, Bauters W, et al. Omalizumab is effective in allergic and nonallergic patients with nasal polyps and asthma. J Allergy Clin Immunol. 2013;131:110-6.

70. Parikh A, Alles R, Hawk L, Pringle M, Darby Y, Scadding GK. Treatment of allergic rhinitis and its impact in children with chronic otitis media with effusion. J Audiol Med. 2000;9:104-17.

71. Umapathy D, Alles R, Scadding GK. A community based questionnaire study on the association between symptoms suggestive of otitis media with effusion, rhinitis and asthma in primary school children. Int J Pediatr Otorhinolaryngol. 2007;71:705-12.

72. Nguyen LH, Manoukian JJ, Sobol SE, Tewfik TL, Mazer BD, Schloss MD, et al. Similar allergic inflammation in the middle ear and the upper airway: evidence linking otitis media with effusion to the united airways concept. J Allergy Clin Immunol. 2004;114:1110-5.

73. Bousquet J, Khaltaev N, Cruz AA, Denburg J, Fokkens WJ, Togias A, et al. Allergic Rhinitis and its Impact on Asthma (ARIA) 2008 update (in collaboration with the World Health Organization, GA(2)LEN and AllerGen). Allergy. 2008;63(Suppl 86):8-160.

74. Klemola T. Deficiency of immunoglobulin A. Ann Clin Res. 1987;19(4):248-57.

75. Aghamohammadi A, Cheraghi T, Gharagozlou M, et al. IgA deficiency: correlation between clinical and immunological phenotypes. J Clin Immunol. 2009;29:130-6.

76. Caffarelli C, Savini E, Giordano S, Gianlupi G, Cavagni G. Atopy in children with otitis media with effusion. Clin Exp Allergy. 1998;28:591-6.

77. Griffin GH, Flynn C, Bailey RE, Schultz JK. Antihistamines and/or decongestants for otitis media with effusion (OME) in children. Cochrane Database Syst Rev. 2006;4:CD003423.

78. Scadding GK, Darby YC, Jansz AJ, Richards D, Tate H, Hills S, et al. Double-blind, placebo controlled randomised trial of medical therapy in otitis media with effusion. Adv Life Sci Health. 2014;1:58-68.

79. Criscuoli G, D’Amora S, Ripa G, Cinquegrana G, Mansi N, Impagliazzo N, et al. Frequency of surgery among children who have adenotonsillar hypertrophy and improve after treatment with nasal beclomethasone. Pediatrics. 2003;111:e236-8.

80. Huang S-W, Giannoni C. The risk of adenoid hypertrophy in children with allergic rhinitis. Ann Allergy Asthma Immunol. 2001;87:350-5.

81. Scadding G. Non-surgical treatment of adenoidal hypertrophy: the role of treating IgE-mediated inflammation. Pediatr Allergy Immunol. 2010;21:1095-106.

82. Guss J, Doghramji L, Reger C, Chiu AG. Olfactory dysfunction in allergic rhinitis. ORL J Otorhinolaryngol Relat Spec. 2009;71:268-72.

83. Klimek L, Eggers $\mathrm{G}$. Olfactory dysfunction in allergic rhinitis is related to nasal eosinophilic inflammation. J Allergy Clin Immunol. 1997; 100:158-64

84. Fonteyn S, Huart C, Deggouj N, Collet S, Eloy P, Rombaux P. Non-sinonasal-related olfactory dysfunction: a cohort of 496 patients. Eur Ann Otorhinolaryngol Head Neck Dis. 2014;131:87-91.
85. Doerfler H, Hummel T, Klimek L, Kobal G. Intranasal trigeminal sensitivity in subjects with allergic rhinitis. Eur Arch Otorhinolaryngol. 2006;263:86-90.

86. Fleiner F, Goktas O. Topical beclomethasone in the therapy of smelling disorders-a new application technique. Indian J Otolaryngol Head Neck Surg. 2011;63:5-9. doi:10.1007/s12070-010-0063-z.

87. Stuck BA, Blum A, Hagner AE, Hummel T, Klimek L, Hörmann K. Mometasone furoate nasal spray improves olfactory performance in seasonal allergic rhinitis. Allergy. 2003;58:1195.

88. Guilemany JM, García-Piñero A, Alobid I, Centellas S, Mariño FS, Valero A, et al. The loss of smell in persistent allergic rhinitis is improved by levocetirizine due to reduction of nasal inflammation but not nasal congestion (the CIRANO study). Int Arch Allergy Immunol. 2012;158:184-90.

89. Rank MA, Kelkar P, Oppenheimer JJ. Taming chronic cough. Ann Allergy Asthma Immunol. 2007;98:305-13.

90. Verguts MM, Eggermont A, Decoster W, de Jong Fl, Hellings PW. Laryngeal effects of nasal allergen provocation in singers with allergic rhinitis. Eur Arch Otorhinolaryngol. 2011;268:419-27. doi:10.1007/s00405-0101420-y [Epub 2010 Nov 12].

91. DelGaudio JM. Steroid inhaler laryngitis: dysphonia caused by inhaled fluticasone therapy. Arch Otolaryngol Head Neck Surg. 2002;128:677-81.

92. Theodouropoulos DS, Ledford DK, Lockey RF, Pecoraro DL, Rodriguez JA, Johnson MC, et al. Prevalence of upper respiratory symptoms in patients with symptomatic gastroesophageal reflux disease. Am J Respir Crit Care Med. 2001;164:72-6.

93. Canonica GW, Bousquet J, Mullol J, Scadding GK, Virchow JC. A survey of the burden of allergic rhinitis in Europe. Allergy. 2007;62(Suppl 85):17-25.

94. Léger D, Annesi-Maesano I, Carat F, Rugina M, Chanal I, Pribil C, et al. Allergic rhinitis and its consequences on quality of sleep: An unexplored area. Arch Intern Med. 2006;166:1744-8.

95. Craig TJ, Teets S, Lehman EB, Chinchilli VM, Zwillich C. Nasal congestion secondary to allergic rhinitis as a cause of sleep disturbance and daytime fatigue and the response to topical nasal corticosteroids. J Allergy Clin Immunol. 1998;101:633-7.

96. Simons FE. Learning impairment and allergic rhinitis. Allergy Asthma Proc. 1996;17:185-9.

97. Baraniuk JN, Clauw DJ, Gaumond E. Rhinitis symptoms in chronic fatigue syndrome. Ann Allergy Asthma Immunol. 1998;81:359-65.

98. Vuurman EF, Vuurman LL, Lutgens I, Kremer B. Allergic rhinitis is a risk factor for traffic safety. Allergy. 2014;69:906-12.

99. Walker S, Khan-Wasti S, Fletcher M, Cullinan P, Harris J, Sheikh A. Seasonal allergic rhinitis is associated with a detrimental effect on examination performance in United Kingdom teenagers: case-control study. J Allergy Clin Immunol. 2007;120:381-7.

100. Chhabra N, Houser SM. Surgery for allergic rhinitis. Int Forum Allergy Rhinol. 2014;4(Suppl 2):S79-83.

101. Allergic rhinitis University of Maryland Medical Center. http://umm.edu/ health/medical/reports/articles/allergic-rhinitis. Accessed 30 July 2015.

102. Jose J, Coatesworth AP. Inferior turbinate surgery for nasal obstruction in allergic rhinitis after failed medical treatment. Cochrane Database Syst Rev. 2010;12:CD005235.

103. Chhabra N, Houser SM. The surgical management of allergic rhinitis. Otolaryngol Clin N Am. 2011;44(3):779-95.

104. Bousquet J, Schünemann HJ, Samolinski B, Demoly P, Baena-Cagnani CE, Bachert C, et al. Allergic rhinitis and its impact on asthma (ARIA): achievements in 10 years and future needs. J Allergy Clin Immunol. 2012;130:1049-62. 